Shaw, C., StitT, J. M. \& Cowan, S. T. (1951). J. gen. Microbiol. 5, 1010-1023.

\title{
Staphylococci and their Classification
}

\author{
By CONSTANCE SHAW, JENNIFER M. STITT AND S. T. COWAN \\ National Collection of Type Cultures, Colindale Avenue, London, N.W. 9
}

SUMMARY: The biochemical and fermentation reactions of 432 strains of aerobic, catalase-positive, Gram-positive cocci were examined in an attempt to produce an orderly classification of the group. The subdivision into Staphylococcus, Micrococcus, Gaffkya and Sarcina could not be justified, and, as Micrococcus is regarded as an invalid generic name, all aerobic species are placed in the genus Staphylococcus with the type species Staph. aureus Rosenbach.

The primary subdivision was made on the coagulase reaction, with secondary subdivisions of the coagulase-negative strains based on the production of acid and acetoin from glucose. The characterization of the subdivisions is presented in a quantitative way.

'The boundaries of the species, whereby $\mathrm{m}^{\mathrm{m}}$ sort them, are made by men.' (Locke, 168v.)

The aerobic catalase-positive Gram-positive cocci present many taxonomic problems which must be resolved before a stable system of nomenclature can be applied to them. We visualize a series of organisms of similar gross morphology that show slight differences in cultural and biochemical reactions, a series that can be likened to a spectrum in that there is a gradual change from the inert non-pathogenic strains to the highly active pathogenic strains.

To test this hypothesis we sought the help of other workers and collected strains from as many sources as possible, and, through the kindness of Dr Ruth E. Gordon, received subcultures of all coagulase-negative strains in the American Type Culture Collection. All strains received, and those in the National Collection of Type Cultures, were put through a standard series of tests which are described in this paper. All cultures were carefully checked for purity, and were dried in vacuo (Rhodes, 1950).

\section{METHODS}

Optimal temperature for growth. Three nutrient agar slopes, spread with a loopful of broth culture, were incubated at 22,30 and $37^{\circ}$. Growth was recorded after 24 and $48 \mathrm{hr}$.

Morphology. Broth cultures incubated at $22^{\circ}$ were examined for packet formation. Smears made from agar cultures incubated at the optimal temperature were stained by Lillie's modification of Gram's method.

Biochemical tests were usually made on cultures incubated at the optimal temperature for growth; if an organism grew equally well at two temperatures, the higher temperature was used. Exceptions to this generalization were tests for the liquefaction of gelatin, and certain retests carried out after the main tests had been completed; details are given in the appropriate section.

Pigment. Strains were grown on potato and on nutritent agar at the optimal temperature for $24 \mathrm{hr}$. and kept at room temperature for a week in diffuse daylight. Pigment was recorded as gold, lemon-yellow, or pink. 
Sensitivity to bacteriophages. Two phages, $\mathbf{K}$ and $\mathbf{W}$, were spotted on to streakinoculations on nutrient agar.

Catalase. 'Ten vol.' $\mathrm{H}_{2} \mathrm{O}_{2}$ was run down the surface of a culture grown on nutrient agar for $24 \mathrm{hr}$. Gas production, however slight, was recorded as positive.

Methylene blue reductase. One drop $1 \%(\mathrm{w} / \mathrm{v})$ aqueous methylene blue was added to $5 \mathrm{ml}$. broth culture ( 1 day at $37^{\circ}, 2$ days at $30^{\circ}$, or 3 days at $22^{\circ}$ ), shaken well to mix, and incubated at $37^{\circ}$ for $2 \mathrm{hr}$. Complete decolorization below the top halfcentimetre was recorded as positive, partial decolorization as a trace reaction.

Hydrolysis of urea. A highly buffered medium in which urea was the only nitrogen source (Stuart, van Stratum \& Rustigian, 1945), and a feebly buffered nutrient urea medium (Christensen, 1946) were used; the second was controlled by a medium of the same composition save that urea was omitted.

Hydrogen sulphide production. Stroke and stab cultures were made on lead acetate agar. In a recheck lead acetate papers were exposed over a broth culture.

Digestion of serum. Organisms were grown on slopes of Loeffler's medium.

Gelatin liquefaction. Stab inoculations were made in $20 \%$ nutrient gelatin; cultures were incubated for 30 days at $22^{\circ}$.

Coagulase test. Equal volumes of $24 \mathrm{hr}$. broth cultures were added to 1/10 dilutions of oxalated plasma. Readings were made after incubation at $37^{\circ}$ for $4 \mathrm{hr}$. and after standing overnight at room temperature.

Litmus milk was incubated for 14 days at $37^{\circ}, 21$ days at $30^{\circ}$, or 28 days at $22^{\circ}$.

Fermentation reactions. Peptone water containing Andrade indicator and $1 \%$ $(\mathrm{w} / \mathrm{v})$ of 'sugar' was used; final readings were made after 14 days at $37^{\circ}, 21$ days at $30^{\circ}$, or 28 days at $22^{\circ}$. The 'sugars' tested were glucose, xylose, galactose, lactose, sucrose, maltose, raffinose, starch, dextrin, glycerol, mannitol, dulcitol and salicin.

The following tests were made on cultures incubated either for 5 days at $37^{\circ}$, 10 days at $30^{\circ}$, or for 14 days at $22^{\circ}$.

Ammonia production from peptone. Cultures were grown in $0.5 \%(\mathrm{w} / \mathrm{v})$ peptone water. An equal volume of Nessler's reagent was added and the colour compared with that produced by the reagent in uninoculated medium of the same batch.

Nitrate reduction. Organisms were grown in nutrient broth containing $0.1 \%(\mathrm{w} / \mathrm{v})$ $\mathrm{KNO}_{3}$. In recheck tests cultures at $37^{\circ}$ were incubated for 10 days. Cultures were tested for nitrites by the Griess-Ilosvay method but, as Wallace $\&$ Neave (1927) have shown, excess nitrite may obscure a positive result by bleaching the red colour. In the recheck dimethyl- $\alpha$-naphthylamine was used in place of $\alpha$-naphthylamine. All negative tests were confirmed by the addition of zinc dust to reduce residual nitrate in the medium (ZoBell, 1932); in a true negative the red colour only appears after the addition of the zinc.

Indole was detected by the Holman \& Gonzales method (1923) based on the oxalic acid reaction (Gnezda, 1899).

Methyl red test (M.R.). Cultures were grown in glucose phosphate peptone medium.

Voges-Proskauer tests (V.P.). Two media were used, glucose phosphate peptone medium and a glucose peptone medium without salt or phosphate (Abd-el-Malek \& Gibson, 1948). The test was carried out by adding $1 \mathrm{ml}$. $40 \%$ (w/v) KOH to $4 \mathrm{ml}$. culture which was then incubated without a plug for $4 \mathrm{hr}$.; a pink fluorescence was recorded as positive. Barritt's (1936) $\alpha$-naphthol method was also used on $1 \mathrm{ml}$. samples of each culture. In the recheck both the foregoing media and an additional medium, glucose peptone medium with $\mathrm{NaCl}$ but without phosphate (Smith, Gordon \& Clark, 1946), were used; cultures were incubated at $30^{\circ}$ for 5 and 10 days and the test was made by Batty-Smith's method (1941).

Utilization of radicals. All tests were made by needle inoculation from a broth culture.

Citrate as sole source of carbon. Koser's citrate medium incubated for 5 days at $37^{\circ}, 10$ days at $30^{\circ}$, or 14 days at $22^{\circ}$. All tubes showing turbidity were confirmed by needle reinoculation into citrate before being recorded as positive. 
Ammonium salt as sole source of nitrogen. Agar slopes made up to Hucker's (1948) formula modified by the substitution of litmus for brom-cresol purple.

\section{Sources of strains}

After eliminating strains that did not come within the definition of the group being studied, we were left with 462 strains. We had several duplicates or variants, such as the Wood strain and its variants Wood 46 and 86 ; all these duplicates were removed, and the number of strains to be classified was reduced to 431. Ninety-one strains were known to be of human origin and 43 were from other animals including dogs (15), sheep (14), and cows (5). Milk (20 strains), ice-cream (95), dairy utensils (21), food (20), air (45), water (5), sewage (2) and soil (4) were represented in our series. The source of 85 strains was unknown; many of these were strains from the American Type Culture Collection (ATCC) or from our own Collection (NCTC).

\section{RESULTS}

Our aim was to classify aerobic Gram-positive catalase-positive cocci, and we discarded certain strains because they did not have these essential characters. Although some strains were micro-aerophilic, none was rejected because it failed to grow in air. On morphological grounds, however, several strains were rejected because they were either diphtheroids, mainly ellipsoidal but occasionally having one axis more than twice the length of the other, or were strains of Nocardia, sometimes coccal and sometimes branched. Among the diphtheroids to be rejected were NCTC 2682 (ATCC 184) Micrococcus rhodochrous, NCTC 2683 (ATCC 412) M. roseus, NCTC 1390 Staphylococcus citreus, NCTC 7650 (A'TCC 8411) M. citreus, NCTC $7502 M$. cinnabareus, and NCTC 2559 M. sphaeroides. A strain of $M$. aurantiacus (ATCC 387) was coccal when grown at $30^{\circ}$, but produced branching rods at other temperatures. M.piltonensis (NCTC 2558) was Gram-negative and was rejected.

We tried to devise a medium that would inhibit the growth of coccal diphtheroids and would allow true cocci to grow. The most successful was a nutrient broth containing $1 \%$ glucose and $2 \%$ sodium taurocholate but occasional diphtheroids grew in it and some cocci were inhibited.

Of the remaining strains it was immediately clear that we were dealing with two entirely different groups; one grew well and produced large opaque colonies, the staphylococcus-micrococcus group; the other grew poorly in air, produced small translucent or semi-opaque colonies, $\alpha$-haemolytic on horse blood agar, and was very feebly catalase-positive. The second group ( $\alpha$-group) of twenty-nine strains will be described more fully in another paper.

The staphylococcus-micrococcus group was reasonably homogeneous and the cultural characters will be discussed briefly.

Morphology. All strains were Gram-positive in young cultures, but many became Gram-negative as the cultures aged. In size the cells ranged from 0.75 to $2.0 \mu$. and varied on different media. In general the cocci were almost spherical but some showed slight elongation. Pleomorphism was commoner than monomorphism but we were unable to subdivide the group on this basis. 
The arrangement of cells was best seen in hanging-drop preparations of broth cultures; paired cocci were the commonest form, and cubical packets the rarest, even in strains named Sarcina species. Motility was uncommon (three strains); when present there appeared to be one flagellum per cell. With two strains motility was best seen in young cultures, but one strain was persistently non-motile until the cultures were 5-7 days old. We did not attempt to stain capsules as our earlier attempts had been unsuccessful even with supposedly capsulated strains (Lyons, 1937).

Temperature range and optima. All strains were able to grow at $\mathbf{2 2}^{\circ}$, most grew at $30^{\circ}$, and the majority grew best at 30 or $37^{\circ}$.

Colony form. On nutrient agar colonies were round, low convex, and opaque. Most strains produced colonies with a smooth surface and an entire edge, but a minority had rough surfaced colonies, and a few produced colonies with undulate or crenated edges.

Pigment. Pigment varied and was not always well developed on agar. Some strains refused to grow on potato but others produced highly coloured pigments.

Growth in broth. Nearly all strains produced a uniform general turbidity and a viscous or powdery deposit. When incubation was extended beyond $24 \mathrm{hr}$. a fine ring pellicle formed on the surface. A few strains failed to produce a general turbidity and these had a granular deposit.

Coagulase tests. All strains were tested with human and rabbit plasma; in addition eighty-four of the coagulase-positive and forty-four coagulasenegative strains were tested with sheep and horse plasma, with the following results :

$\begin{array}{lcc}\text { Eighty-four } & \begin{array}{c}\text { Forty-four } \\ \text { coagulase-positive } \\ \text { strains }\end{array} & \begin{array}{c}\text { coagulase-negative } \\ \text { strains }\end{array} \\ \text { human } & \mathbf{8 4} & 0 \\ \text { rabbit } & \mathbf{8 4} & 0 \\ \text { sheep } & \mathbf{6 1} & 0 \\ \text { horse } & \mathbf{8 2} & 0\end{array}$

All plasma was from recently drawn blood, so that age could not account for the smaller number of positives with the sheep plasma.

Sensitivity to phages $\boldsymbol{K}$ and $W$. Phage $\mathrm{K}$ lysed nearly all coagulase-positive and many coagulase-negative strains. $W$ phage was more selective and acted mainly on coagulase-negative strains.

Hydrolysis of urea. Christensen's urea medium (1946) is much more sensitive than that of Stuart et al. (1945); it does not give false reactions by alkali production from other constituents in the medium. Most strains were found to hydrolyse urea.

$\mathrm{H}_{2} \mathrm{~S}$ production. Some strains produced a trace of $\mathrm{H}_{2} \mathrm{~S}$ but few caused extensive blackening of the lead acetate medium.

Digestion of serum. This is not a characteristic of the group as a whole.

Gelatin liquefaction is more rapid in strains of human or animal origin than in those from other sources. With a time limit of $\mathbf{3 0}$ days a number of strains are recorded as negative that might have become positive if incubation had been continued (Hucker, 1924a). 
Litmus milk. Acid production was closely correlated with lactose-fermentation; clots were of the acid and the rennet types.

Fermentation reactions. Most strains produced acid from glucose and several other sugars. In certain 'sugars', such as dulcitol and dextrin, a transient acidity was produced which later reverted to alkalinity.

Ammonia production from peptone. This is an unsatisfactory test; all batches of peptone water give a positive reaction of greater or less intensity when Nessler's reagent is added. We found one batch of Evans peptone that gave only a trace reaction and kept this batch for all subsequent tests. Even in one strain the ability to produce ammonia from peptone seemed to be a variable character and we did not place much reliance on the results we obtained.

Reduction of nitrate. Some irregular results obtained in the first tests were eliminated by using dimethyl- $\alpha$-naphthylamine. The use of zinc dust was invaluable in checking apparently negative tests.

Indole. None of the strains produced indole.

M.R. Most strains gave a positive reaction but there were several borderline reactions and in these variable results were obtained when the tests were repeated.

V.P. More positives were obtained with the unbuffered media and the $\alpha$-naphthol test. Batty-Smith's (1941) method is so sensitive that the test may lose its differential value, but it is clearly the most reliable indicator of acetoin production.

Methylene blue reduction. Most strains reduced methylene blue added to broth cultures; we tried the semi-solid methylene blue medium used by Smith et al. (1946) but this had no greater differential value.

\section{Utilization of radicals}

(a) Citrate as the sole source of carbon. Few strains were able to grow in Koser's citrate medium.

(b) Ammonium salt as the sole source of nitrogen. Less than half the strains were able to grow on the medium, and at first it seemed that this test might have differential value. However, repetition of the test did not always give the same result, which suggested that needle inoculation was not always satisfactory in avoiding the carry-over of nutritional factors.

\section{CLASSIFICATION OF THE GROUP}

'The genus Micrococcus provides what is probably the worst example in bacteriology of uncritical systematic work.' (Abd-el-Malek \& Gibson, 1948.)

If we assume that the strains examined are typical of the group they purport to represent, we should be able to use the results as a basis for the classification of the group. If, on the other hand, our strains are not typical or have been derived from too few and insufficiently varied sources, any classification we formulate will not give a true picture of the group as a whole. Some strains had been in culture collections for several years and may not now be typical, but the majority were dried soon after isolation and these are likely to have 
retained their original characters. As to source, our strains came from man and animals, from food, milk, milk-products, and dairy utensils. To these we added airborne contaminants found on plates of other cultures, strains from air collected by a slit sampler, and a few strains we isolated from water and soil.

We have mentioned that the $\alpha$-group appears to be distinct from the staphylococcus-micrococcus group, and we should consider how its removal will affect the variety of our sources. The $\alpha$-group consists essentially of strains from air samples and strains from dairy utensils, but it should not be inferred that all strains from air and from dairy utensils are of this type; these strains were sent to us because they were unusual. We received strains from dairy utensils and dairy products from Dr T. Gibson's collection, and these fall naturally into our staphylococcus-micrococcus group, as do those from Dr G. J. Hucker and from the American Type Culture Collection. We feel justified, therefore, in assuming that our strains are not only typical but are representative of the group as a whole.

Our next task is to decide how the staphylococcus-micrococcus group should be subdivided. One line of cleavage is clear, that made by the coagulase test, which separates the toxigenic and pathogenic strains sharing a series of common antigens (Hobbs, 1948) and sensitive to a series of specific bacteriophages (Wilson \& Atkinson, 1945) from the non-toxigenic and nonpathogenic of diverse antigenic make-up (Cowan, 1938) and not susceptible to bacteriophages specific for coagulase-positive strains. We choose the coagulase test because it is simpler to demonstrate than are the specific toxins.

We attempted to subdivide the coagulase-positive subgroup; Cowan (1938) suggested that the V.P. reaction might be useful, but by using different media and more sensitive reagents we found that nearly all animal strains produce acetoin. Coagulase-positive strains can be subdivided by the toxins they produce; human strains seldom produce $\beta$-toxin and many animal strains do so, but we do not think that this subdivision is profitable, and we are content to leave the coagulase-positive strains as a fairly homogeneous subgroup entitled to specific rank. We do not consider pigmentation to have even varietal value in this species.

Division of the coagulase-negative subgroup presented greater difficulty; the ability to utilize $\mathrm{NH}_{3}$ salts was found useful by Hucker $(1924 b, 1948)$, while Abd-el-Malik \& Gibson (1948) divided their strains primarily on heat resistance and fermentative ability. We did not use a heat-resistance test because we were not convinced that the methods in use were sufficiently reliable to give reproducible results, but the ability or inability to ferment sugars seemed to us to be a good starting-point in the subdivision.

We drew up a preliminary classification using $\mathrm{NH}_{3}$ salt utilization and the M.R. test, but the two distinguishing characters were variable in too many strains; we then rearranged our fermenting strains into a series of subgroups divided primarily on acetoin formation, with lactose and mannitol fermentation as secondary differential characters. Again, the groupings were unsatisfactory, and, apart from the differential criteria themselves, there was little homogeneity within a group. Finally, we divided our coagulase-negative 
strains according to the following scheme, in which the differential criteria are characters that seldom show variation when strains are re-examined; this grouping brings together strains with several characters in common. Like all other classifications of the cocci, it is arbitrary and artificial.

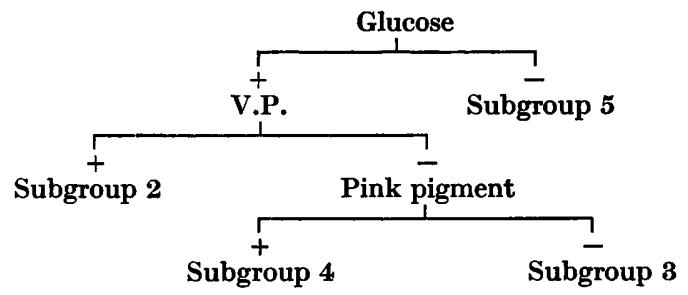

Characteristics of the subgroups so far defined are shown in Table 1; subgroup 1 consists of coagulase-positive strains; subgroups 2-5 of coagulasenegative. The $\alpha$-group is included for comparison with the other subgroups. The figures show the percentage of strains producing the reaction indicated; caution should be exercised in accepting these too literally as most are based on small numbers within each subgroup.

\section{Correlation of grouping and source of strains}

We did not attempt to correlate our groups with the source of the strains until the grouping seemed satisfactory on other grounds. We believe that the source of a culture should not have a place in any bacterial classification scheme, but present Table 2 for those whose opinion differs from ours. Subgroups 1 and 2 were chiefly represented by strains from animals or from material likely to be contaminated by animals, subgroup 3 from dairy products. Subgroups 4 and 5 were nearly all strains of unknown origin from culture collections, and many of these were named species.

\section{Distribution of named strains}

Apart from the strains freshly isolated from ice-cream, dairy utensils, and air, most of the strains had been assigned to particular species. The cultural characters of the named strains did not always correspond to the description of the species. As many of these strains are available in culture collections, the more important are listed in Table 3. Most strains in subgroup 1 were named Staph. pyogenes or Staph. aureus, and are not shown in the table. We did not have any typical strains of Micrococcus tetragenus.

\section{DISCUSSION}

The value of a classification lies in its usefulness; can it be said that any classification of these aerobic cocci will serve a useful purpose? The medical bacteriologist wants only to classify pathogenic strains, the dairy bacteriologist those of economic importance in milk, dairy products, and dairy hygiene. Should each type of bacteriologist be allowed to develop his own classification or should some attempt be made to classify within one system the group as a whole? We believe that this attempt is worthwhile, and we have made it. 
Table 1. Cultural characters of subgroups

No. of strains

Opt. temperature: $\mathbf{2 2}^{\circ}$

$30^{\circ}$

Pigment: none

gold

yellow

pink

$\mathrm{NH}_{3}$-salt utilization

M.R., positive

V.P., positive

$\mathbf{N H}_{3}$ from peptone

$\mathrm{H}_{2} \mathrm{~S}$ produced

Nitrates reduced

Methylene blue reduced

Litmus milk: acid acid clot digestion

Gelatin liquefied litmus decolorized

Serum digested

Coagulase-positive

Acid from: glucose

xylose

galactose

lactose

sucrose

maltose

raffinose

starch

dextrin

glycerol

mannitol

dulcitol

salicin

Urea hydrolysed

Sensitivity to phage $K$

Sensitivity to phage $W$
Subgroup

\begin{tabular}{|c|c|c|c|c|c|}
\hline 1 & 2 & $\mathbf{3}$ & 4 & 5 & $\alpha$ \\
\hline 143 & 149 & 63 & 16 & 31 & 29 \\
\hline 0 & 0 & $\mathbf{0}$ & 25 & 10 & 0 \\
\hline 2 & 7 & 38 & 69 & 42 & 34 \\
\hline 98 & 93 & 62 & 6 & 48 & 66 \\
\hline 25 & 55 & 51 & 0 & 29 & 100 \\
\hline 69 & 38 & 30 & $\mathbf{0}$ & 13 & 0 \\
\hline 6 & 7 & 19 & 0 & 45 & 0 \\
\hline 0 & 0 & $\mathbf{0}$ & 100 & 13 & 0 \\
\hline 0 & 27 & 51 & 88 & 74 & 52 \\
\hline 99 & 88 & 68 & $\mathbf{0}$ & $\mathbf{0}$ & 93 \\
\hline 94 & 100 & 0 & 0 & 0 & o \\
\hline 98 & 88 & 92 & 56 & 84 & 0 \\
\hline 27 & 14 & 10 & $\mathbf{0}$ & 29 & o \\
\hline 97 & 73 & 83 & 75 & 26 & $\mathbf{0}$ \\
\hline 100 & 99 & 94 & 19 & 71 & 83 \\
\hline 94 & 62 & 73 & $\mathbf{0}$ & $\mathbf{0}$ & 93 \\
\hline 56 & 35 & 41 & 0 & 0 & $\mathbf{0}$ \\
\hline 4 & 5 & 2 & 0 & 0 & 0 \\
\hline 40 & 22 & 27 & $\mathbf{0}$ & $\mathbf{0}$ & O \\
\hline 100 & 51 & 63 & 6 & 71 & 0 \\
\hline 26 & 6 & 0 & 0 & 0 & o \\
\hline 100 & $\mathbf{0}$ & $\mathbf{0}$ & $\mathbf{0}$ & 0 & 0 \\
\hline 100 & 100 & 100 & 100 & 0 & 100 \\
\hline 3 & 11 & 62 & 0 & 0 & 41 \\
\hline 98 & 83 & 78 & 0 & 0 & 97 \\
\hline 98 & 67 & 81 & 0 & 0 & 97 \\
\hline 100 & 99 & 83 & 44 & 0 & 97 \\
\hline 100 & 98 & 87 & 13 & 0 & 100 \\
\hline 3 & 1 & 17 & $\mathbf{0}$ & 0 & 31 \\
\hline 6 & 4 & 3 & 19 & $\mathbf{0}$ & 27 \\
\hline 77 & 32 & 22 & 19 & 0 & 38 \\
\hline 94 & 95 & 79 & 6 & 0 & 97 \\
\hline 97 & 75 & 70 & 25 & 0 & 69 \\
\hline 3 & 2 & $\mathbf{3}$ & 0 & 0 & 0 \\
\hline 22 & 13 & 51 & 6 & $\mathbf{0}$ & 83 \\
\hline 85 & 77 & 67 & 44 & 26 & 0 \\
\hline 83 & 22 & 21 & $\mathbf{0}$ & $\mathbf{0}$ & 0 \\
\hline 1 & $\mathbf{9}$ & 0 & 0 & 0 & 0 \\
\hline
\end{tabular}

Figures show percentage of strains giving the reaction.

Table 2. Source of strains

\begin{tabular}{lrrrrrr}
\multicolumn{7}{c}{ Subgroup } \\
Surce & 1 & 2 & 3 & 4 & 5 & $\alpha$ \\
Other animals & 60 & 25 & 2 & 0 & 4 & 0 \\
Ice-cream & 34 & 4 & 5 & 0 & 0 & 0 \\
Milk and dairy utensils & 4 & 66 & 25 & 0 & 0 & 0 \\
Food & 4 & 5 & 13 & 0 & 0 & 16 \\
Air & 1 & 26 & 4 & 0 & 1 & 0 \\
Water, soil, sewage & 0 & 2 & 4 & 0 & 1 & 12 \\
Unknown & 33 & 10 & 5 & 16 & 21 & 0
\end{tabular}


Table 3. Distribution of named strains in the subgroups

Collection nos.

\begin{tabular}{|c|c|c|c|}
\hline Name & ATCC & NCTC & Subgrou \\
\hline M. agilis & 998 & 2676 & 5 \\
\hline M. agilis & - & 3874 & $\mathbf{5}$ \\
\hline M. candicans & 8406 & 7558* & 2 \\
\hline M. candiçans & 8407 & $7559 *$ & 2 \\
\hline M. candicans & 8456 & 7733 & $\mathbf{5}$ \\
\hline M. candicans & - & 1657 & 5 \\
\hline M. caseolyticus & 8460 & $7735 *$ & 1 \\
\hline M. cereus & 一 & $\mathbf{3 8 8 1}$ & $\mathbf{5}$ \\
\hline M. conglomeratus & 401 & 2677 & $\mathbf{3}$ \\
\hline M. corallinus & 966 & $7509 *$ & 4 \\
\hline $\begin{array}{l}\text { M. cremoris- } \\
\text { viscosi }\end{array}$ & - & 963* & 3 \\
\hline M. flavo-roseus & 397 & 7528 & 4 \\
\hline M. flavus & 400 & 2678* & $\mathbf{5}$ \\
\hline M. flavus 1 & 10240 & $7743^{*}$ & $\mathbf{5}$ \\
\hline M. freudenreichii & $i \quad 407$ & 2679* & 5 \\
\hline M. freudenreichii & - & 3880* & $\mathbf{5}$ \\
\hline M. lactis-viscosus & - & $3873^{*}$ & $\mathbf{2}$ \\
\hline M. liquefaciens & - & 2654 & 2 \\
\hline M. luteus & 379 & 2680* & 5 \\
\hline M. luteus & 398 & 2681* & 5 \\
\hline M. lysodeikticus & 4698 & 2665 & $\mathbf{5}$ \\
\hline M. roseus & 144 & 7511 & 4 \\
\hline M. roseus & 177 & 7512 & 4 \\
\hline M. roseus & 178 & 7513 & 4 \\
\hline M. roseus & 179 & 7514 & 4 \\
\hline M. roseus & 185 & 7515 & 4 \\
\hline M. roseus & 388 & 7516 & 4 \\
\hline M. roseus & 412 & 7517 & 4 \\
\hline M. roseus & 416 & 7518 & 4 \\
\hline M. roseus & 417 & 7519 & 4 \\
\hline
\end{tabular}

\begin{tabular}{l}
\multicolumn{1}{c}{ Name } \\
M. roseus \\
M. roseus \\
M. roseus \\
M. roseus \\
M. rubens \\
M. sulphureus \\
M. tetragenus \\
M. tetragenus \\
M. tetragenus \\
M. ureae \\
M. varians \\
M. varians \\
M. vernae \\
Sar. aurantiaca \\
Sar. flava \\
Sar. flava \\
Sar. lutea \\
Sar. lutea \\
Sar. ureae \\
Staph. citreus \\
Staph. citreus \\
Staph. citreus \\
Staph. epidermidis \\
Staph. epidermidis- \\
albus \\
Staph. epidermidis- \\
albus \\
Staph. flavo-cyaneus \\
Staph. salivarius \\
Staph. viscidus \\
\end{tabular}

Collection nos.

* These strains differ significantly from the usual description of the species named.

We must first consider the group as a whole and decide on its rank; is it sufficiently homogeneous for generic status? We would remove the $\alpha$-group of cocci for these seem to differ fundamentally from the other strains; a reasonably homogeneous group remains but should it be subdivided at the generic level? Cowan \& Shaw (1949), in describing their classification of Staphylococcus, discussed this problem, particularly in relation to restricting the genus Staphylococcus to the potentially pathogenic strains. We searched for some other characteristic to correlate with coagulase-production, toxigenicity, and pathogenicity, and we have failed to find it; we conclude, therefore, that coagulase-positive and coagulase-negative staphylococci should for the present be included in the same genus. Is there any justification for subdividing the coagulase-negative strains at the generic level? We do not think so, and suggest that the whole group should be considered as one genus.

Cummins \& Cummins (1913) found fermentation tests were unreliable and inconstant; Ferguson Wood (1950) has shown what every worker has suspected, that when a pure culture is plated it is unusual for two colonies to give exactly the same reactions when individual colonies are put through a number of 
fermentation and biochemical tests. It is clear, therefore, that no hard-andfast lines of demarcation can be drawn between different subgroups and that each must be defined on a quantitative basis.

The subdivisions of our classification were made after we had found that the species recognized by Hucker $(1924 b, 1928,1948)$ were meaningless. Abd-el-Malik \& Gibson (1948) suggested that acetoin production was a valuable differentiating criterion; we found this to be one of the most constant characters of a strain, and, after separating the non-fermenting strains, used it as the main differential test.

It is impossible to make a direct comparison between our classification and that of Hucker as we used different criteria, but, by an exchange of cultures with Dr Gibson, fifteen strains were classified according to our two schemes. Six strains labelled groups IIA, IIB or IIC by Gibson fell into our subgroup 5; six strains of his groups IIIA or IIIB were our subgroup 3. Three other strains of our subgroup 3 were intermediates in Gibson's scheme; two strains were II-III and the third (NCTC 963) a I-II intermediate. Non-fermenting strains form group II of Gibson's classification, and explain why our subgroup 3 seems to show a spread over his groups. We think our arrangement is the more logical; the subgroups 1-5 show a gradual transition from the biochemically active strains of subgroup 1 to the inactive strains of subgroup 5. The results support our original hypothesis that these cocci can be arranged in some order so that their reactions show all the gradations of a spectrum.

Subgroup 2 seems to be the coagulase-negative counterpart of subgroup 1. Between subgroups 2 and 3 there are significant differences; strains of subgroup 2 grow best at $37^{\circ}$, produce acetoin, seldom ferment xylose or salicin, and seldom produce lemon-yellow pigments. Subgroup $\mathbf{3}$ is more often characterized by a lower optimal temperature, a higher proportion of strains ferment xylose and salicin, and more strains produce yellow pigment. Subgroup 4, the glucose-fermenting strains that produce a pink pigment, seem to form a link between subgroup 3 and the inactive subgroup 5.

Can each of these subgroups (2-5) be given specific status? Mannitol fermentation was used in the classification of these cocci by Andrewes \& Gordon (1907), Dudgeon (1908), Julianelle (1937), Chapman, Lieb \& Curcio (1938), and by others; it was not considered of value by Winslow \& Winslow (1908), or by Winslow, Rothberg \& Parsons (1920). With glucose, it appears to be one of the most constant of the fermentation reactions (Blair, 1938) and these have the greatest claim to differential value of all the 'sugar' tests. We accept glucose fermentation as a differential test; but mannitol fermentation seems to have more limited value.

Pigmentation has long been the main differential character in this genus. We found that the pigmentation of strains in subgroups 3-5 remained constant in cultures maintained on media for many years; pigmented strains of groups 1-2, however, continually threw off stable non-pigmented (white) variants; the pigmented form could only be retained by careful colony selection and maintenance of the culture in dried form. It is seldom possible to classify old strains of these groups by pigmentation, and, as freshly-isolated pathogens 
may be devoid of pigment, we think this criterion should be used only for the differentiation of the relatively inactive strains of subgroups 3-5. The pink pigment producers of subgroup 4 are remarkably constant, and in this group we have never observed a non-pigmented variant. On the other hand, the pink strains in subgroup 5 were less constant in pigmentation.

\section{NOMENCLATURE}

With the exception of the $\alpha$-group our series is regarded as being of one genus. The genus as we shall define it is a combination of species of several genera; it includes species of Sarcina, Micrococcus, Staphylococcus, Gaffkya and Rhodococcus, but excludes the strictly anaerobic species. The Winslows (1908, pp. 104, 106) retained the genus Sarcina because the name was 'firmly intrenched in the literature and usage of bacteriology' (p. 228), although they admitted that packet formation was an inconstant character. We would restrict the generic name Sarcina to the strictly anaerobic Gram-positive cocci. The characterization of the genus Micrococcus Cohn, 1872, was based on several different types of micro-organism, including species now known by the names Chromobacterium prodigiosum, Chrom. violaceum and Pseudomonas pyocyanea. Rule 24. (7) of the Bacteriological Code (Buchanan, St John-Brooks \& Breed, 1948) states that the name of a taxonomic group (taxon) is illegitimate if 'the characterization of the group was based upon an impure or mixed culture'. We do not think that this rule is abused if it is interpreted to make the generic name Micrococcus Cohn illegitimate on the grounds that the characterization was based on cultures of different types. A type species was not chosen by Cohn but the first-named species, $M$. prodigiosus, implies that if the generic name is valid it should replace the name Chromobacterium. Although we have the weight of Buchanan's (1915) opinion against us, we reject the generic name Micrococcus in the belief that our interpretation of Rule 24 (7) is correct. The name Staphylococcus was used by Ogston (1882), who clearly differentiated the pigmented cluster-forming cocci from the streptococci. Rosenbach (1884, p. 18) accepted Ogston's name and adopted it for a group of two provisional types (für eine Gruppe von vorläufig 2 Einzelarten) which he proposed to name, according to the botanical system, Staphylococcus flavus or aureus and Staph. albus. He described these species under the trinomials Staph. pyogenes aureus (p. 19) and Staph. pyogenes albus (p. 21), but later (p. 27) reverted to the binomial Staph. aureus.

Our subgroup 1 can be identified as Staph. aureus Rosenbach and subgroup 4 , as Micrococcus roseus. Fairbrother (1940) used the name Staph. saprophyticus for coagulase-negative strains of human and animal origin and, although he said they were usually non-fermenters of mannitol, we suggest that this is a suitable name for our subgroup 2. It has the advantage that it avoids a name descriptive of a pigment.

Subgroup 3 probably includes several previously described species; rule 19 of the Code requires that the oldest legitimate epithet should be retained. Abd-el-Malik \& Gibson (1948) have indicated the confusion attached to such names as $M$. luteus and $M$. varians, and we think that further confusion will 
arise if we attach to our subgroups names that are in current use for inadequately characterized species. Subgroup 3 we designate as Staph. lactis n.sp. Subgroup 4 strains form the pink pigmented species; the Winslows (1908) gave this group generic rank but apart from pigment the group forms a natural connecting link between subgroups 3 and 5 . Ten of our strains were labelled $M$. roseus and we see no reason for changing the specific epithet.

The non-fermenting, biochemically inactive strains of subgroup 5 are common in nature but, because of inadequate characterization in the earlier literature, they are difficult to name. Castellani once sent a culture (now dead) labelled Staph. afermentans to the NCTC but we have not found this name in the literature. We think it is an appropriate name and use it for subgroup 5, ascribing it to Castellani.

\section{DEFINITIONS}

To give greater precision to our definitions each is divided into two parts, essential characters, and usual or variable characters. A type culture of Staph. aureus Rosenbach has never been selected; we have designated type cultures of this species and of the others we have defined, together with the corressponding catalogue numbers in this Collection (Rule 9, Recommendation $9 d$ ).

\section{Staphylococcus Rosenbach}

Essential characters. Gram-positive spheres in pairs or irregular clusters. Catalasepositive. Aerobic and facultatively anaerobic; never strictly anaerobic. Not acidfast. Gas never produced from the breakdown of carbohydrates.

Usual and variable characters. Usually non-motile and non-sporing. Many strains are active fermenters of carbohydrates, some are proteolytic. Most strains grow in medium containing $10 \% \mathrm{NaCl}$.

Type species. Staphylococcus aureus Rosenbach emend.

Species (i). Staphylococcus aureus Rosenbach emend.

Essential characters of the genus. Coagulase-positive (human or rabbit plasma). Acid produced from glucose.

Usual characters. Colonies usually coloured golden-yellow or cream; white colonies occur frequently as variants and may be the only type present in a culture. Lemonyellow strains are rare. Usually produce acetoin, reduce nitrates and methylene blue, and liquefy gelatin. Usually hydrolyse urea and acidify milk.

Type strain. FDA 209-P (ATCC 7538P, NCTC 7447).

Species (ii). Staphylococcus saprophyticus Fairbrother emend.

Essential characters of the genus. Coagulase-negative. Acid and acetoin produced from glucose.

Usual characters. Colonies usually not pigmented. Usually reduce nitrates and methylene blue, hydrolyse urea, liquefy gelatin and acidify milk.

Type strain. S 41 (NCTC 7292).

Species (iii). Staphylococcus lactis n.sp.

Essential characters of the genus. Coagulase-negative. Acid produced from glucose. Acetoin not produced. Colonies not pink.

Usual characters. Cells often arranged in tetrads or packets. Usually reduce nitrates and methylene blue. Liquefaction of gelatin and hydrolysis of urea variable.

Type strain. G33 (NCTC 7564) 
Species (iv). Staphylococcus roseus Tavel.

Essential characters of the genus. Coagulase-negative. Produce acid from glucose; acetoin not produced. Produce pink colonies on agar.

Usual characters. Usually reduce nitrates but not methylene blue. Usually do not hydrolyse urea, liquefy gelatin, or acidify milk.

Type strain. ATCC 418 (NCTC 7520).

Species (v). Staphylococcus afermentans ex Castellani.

Essential characters of the genus. Coagulase-negative. Do not produce acid or acetoin from glucose.

Usual characters. Usually do not reduce nitrates or hydrolyse urea. Methylene blue reduced. Gelatin usually liquefied.

Type strain. NCTC 2665 (Micrococcus lysodeikticus Fleming).

We wish to acknowledge our indebtedness to the many workers who sent us strains, and especially to Dr Ruth Gordon and Dr T. Gibson for their co-operation. Dr Gibson's knowledge of the older literature was invaluable in dealing with the problems of nomenclature. Most of the work was done at the Lister Institute of Preventive Medicine, Elstree, and we are grateful to the long-suffering staff of the media room there.

\section{REFERENCES}

AbD-el-Malex, Y. \& Gibson, T. (1948). Studies in the bacteriology of milk. II. The staphylococei and micrococci of milk. J. Dairy Res. 15, 249.

ANDrewes, F. W. \& Gordon, M. H. (1907). Report on the biological characters of the staphylococci pathogenic for man. 35th Ann. Rep. loc. Govt. Bd., Rep. med. Off., 1905-6, App. B, no. 7, p. 543.

BarritT, M. M. (1936). The intensification of the Voges-Proskauer reaction by the addition of $\alpha$-naphthol. J. Path. Bact. 42, 441.

BATTY-Smith, C. G. (1941). The detection of acetyl-methyl-carbinol in bacterial cultures. A comparative study of the methods of O'Meara and of Barritt. J. Hyg., Camb., 41, 521.

BLAIR, J. E. (1938). The stability of biological and biochemical properties of staphylococci. J. Bact. 35, 52.

Buchanan, R. E. (1915). Nomenclature of the Coccaceae. J. infect. Dis. 17, 528.

Buchanan, R. E., St John-Brooks, R. \& Breed, R. S. (1948). International Bacteriological Code of Nomenclature. J. Bact. 55, 287. Reprinted in $J$. gen. Microbiol. 3, 444.

Chapman, G. H., Lieb, C. W. \& Curcio, L. G. (1938). The use of bromthymol blue agar and phenol red mannitol agar for the isolation of pathogenic types of staphylococci. Amer. J. clin. Path. 8, 3.

Christensen, W. B. (1946). Urea decomposition as a means of differentiating Proteus and paracolon cultures from each other and from Salmonella and Shigella types. J. Bact. 52, 461.

Coнn, F. (1872). Untersuchungen über Bacterien. Beitr. Biol. Pflanz, 1, Heft 2, 127.

Cowan, S. T. (1938). The classification of staphylococci by precipitation and biological reactions. J. Path. Bact. 46, 31.

Cowan, S. T. \& Shaw, C. (1949). Outline classification of Bacterium and Staphylococcus. J. gen. Microbiol. 3, 69.

Cummrns, S. L. \& Cummins, C. C. (1913). A preliminary note on the differentiation of staphylococci. J. R. Army med. Cps, 20, 499.

Dudgeon, L. S. (1908). The differentiation of the staphylococci. J. Path. Bact. 12, 242.

Fairbrother, R. W. (1940). Coagulase production as a criterion for the classification of the staphylococci. J. Path. Bact. 50, 83. 
Ferguson Wood, E. J. (1950). The classification of bacteria. With special reference to non-pathogenic eubacteria. Proc. Linn. Soc., N.S.W., 75, 158.

GNEZda, J. (1899). Sur les reactions nouvelles des bases indoliques et des corps albuminoides. C.R. Acad. Sci., Paris, 128, 1584.

Hoвbs, B. C. (1948). A study of the serological differentiation of Staphylococcus pyogenes. J. Hyg., Camb., 46, 222.

Holman, W. L. \& Gonzales, F. L. (1923). A test for indol based on the oxalic reaction of Gnezda. J. Bact. 8, 577 .

Hucker, G. J. (1924a). Studies on the Coccaceae. II. A study of the general characters of the micrococi. Tech. Bull. N.Y. St. agric. Exp. Sta. no. 100.

Hucker, G. J. (1924b). Studies on the Coccaceae. IV. The classification of the genus Micrococcus Cohn. Tech. Bull. N.Y. St. agric. Exp. Sta. no. 102.

Hucker, G. J. (1928). Studies on the Coccaceae. IX. Further studies on the classification of the micrococci. Tech. Bull. N.Y. St. agric. Exp. Sta. no. 135.

Hucker, G. J. (1948). In Bergey's Manual of Determinative Bacteriology. 6th ed. p. 235. Edited by Breed, R. S., Murray, E. G. D. \& Hitchens, A. P. London: Baillière, Tindall and Cox.

Julianelle, L. A. (1937). Determination of staphylococcal types by fermentation of mannite. Proc. Soc. exp. Biol., N.Y., 36, 117.

Locke, J. (1689). An Essay Concerning Human Understanding. Book III, chapter vi.

Lyons, C. (1937). Antibacterial immunity to Staphylococcus pyogenes. Brit. J. exp. Path. 18, 411 .

Ogston, A. (1882). Micrococcus poisoning. J. Anat., Lond., 17, 24.

RHodes, M. (1950). Viability of dried bacterial cultures. J. gen. Microbiol. 4, 450.

Rosenbach, F. J. (1884). Mickro-organismen bei den Wund-Infections-Krankheiten des Menschen. Wiesbaden: J. F. Bergmann.

Smith, N. R., Gordon, R. E. \& Clark, F. E. (1946). Aerobic sporeforming bacteria. Misc. Publ. U.S. Dep. agric. no. 559.

Stuart, C. A., Stratum, E. van \& Rustigian, R. (1945). Further studies on urease production by Proteus and related organisms. J. Bact. 49, 437.

Wallace, G. I. \& Neave, S. L. (1927). The nitrite test as applied to bacterial cultures. J. Bact. 14, 377.

Wilson, G. S. \& Atkinson, J. D. (1945). Typing of staphylococei by the bacteriophage method. Lancet, i, 647.

Winslow, C.-E. A., Rothberg, W. \& Parsons, E. I. (1920). Notes on the classification of the white and orange staphylococci. J. Bact. 5, 145.

Wrnslow, C.-E. A., \& Wrnsuow, A. R. (1908). The Systematic Relationships of the Coccaceae. New York: John Wiley and Sons.

ZoBell, C. E. (1932). Factors influencing the reduction of nitrates and nitrites by bacteria in semi-solid media. J. Bact. 24, 273.

(Received 6 June 1951) 